This is an open access article under the CC BY-NC-ND license (https://creativecommons.org/licenses/by-nc-nd/3.0/) Issue III, November 2020

ISSN 2707-9481

ISBN 978-601-323-207-2

https://doi.org/10.31643/2020.028

\author{
Knyazov Yerlan \\ Researcher, Labor Safety Regulation Laboratory \\ RSE on PVC "Republican Scientific Research Institute for Labor Protection of the Ministry of Labor and \\ Social Protection of the Population of the Republic of Kazakhstan" \\ Nur-Sultan, Republic of Kazakhstan \\ E-mail: nauka@rniiot.kz \\ ORCID ID https://orcid.org/0000-0002-5825-3372
}

\title{
On the state of industrial injuries at agricultural enterprises in Kazakhstan
}

\begin{abstract}
The relevance of this topic is due to the fact that today a large place in the system of life safety is occupied by industrial injuries. In agriculture, injury rates are affected by the specificity of this branch of the economy, associated with the seasonality of work in the open air, with non-normality of the working day and other distinctive working conditions. The purpose of this work was to assess injuries associated with the causes of accidents in agriculture, as well as the need to identify sources of injury to workers, develop and implement measures to prevent them. Statistics from the Bureau of national statistics of the Agency for strategic planning and reforms of the Republic of Kazakhstan were used to assess injuries in agriculture. The state of injuries, types and causes of injuries in agriculture are considered. Measures aimed at preventing accidents and injuries at agricultural enterprises are analyzed.
\end{abstract}

Keywords: injuries, measures, causes, injury prevention, accident, safe technologies.

Cite this article as: Knyazov Y. (2020). O sostoyanii proizvodstvennogo travmatizma na sel'skokhozyaystvennykh predpriyatiyakh Kazakhstana [On the state of industrial injuries at agricultural enterprises in Kazakhstan]. Challenges of Science. Issue III, p.: 185-189. (In Russian). https://doi.org/10.31643/2020.028

\section{Князов Ерлан Жаксыбаевич}

РГП на ПХВ «Республиканский научно-исследовательский институт по охране труда Министерства труда и социальной защиты населения РК», Научный сотрудник лаборатории регламентации в области охраны труда

Республика Казахстан, г.Нур-Султан

E-mail: nauka@rniiot.kz

ORCID ID https://orcid.org/0000-0002-5825-3372

\section{О состоянии производственного травматизма на сельскохозяйственных предприятиях Казахстана}

\footnotetext{
Абстракт. Актуальность данной темы обусловлена тем, что в наши дни большое место в системе безопасности жизнедеятельности занимает производственный травматизм. В сельском хозяйстве на показателях травматизма сказываются специфичность данной отрасли экономики, связанный с сезонностью проведения работ под открытым небом, с не нормативностью рабочего дня и другими отличительными условиями труда. Целью данной работы явилось оценка травматизма связанные с причинами несчастных случаев в сельском хозяйстве, а также необходимость выявления источников травмирования работников,
} 
разработки и внедрения мероприятий по их предотвращению. Для проведения оценки травматизма в сельском хозяйстве использовались статистические данные Бюро национальной статистики Агентства по стратегическому планированию и реформам РК. Рассмотрены состояние травматизма, виды и причины травматизма в сельском хозяйстве. Проанализированы мероприятия направленные на профилактику несчастных случаев и травматизма на сельскохозяйственных предприятиях.

Ключевые слова: травматизм, мероприятия, причины, профилактика травматизма, несчастный случай, безопасные технологии.

Международная Организация Труда отмечает, что во всем мире проблема производственного травматизма не осознается в полной мере. Возможно причина в том, что несчастный случай (НС) на производстве не так очевидны. Ведь только часть из них, как правило, это наиболее тяжелые случаи, придаются громкой огласке. При этом в повседневной жизни мало кто обращает внимание на тех, кто в последствие умер или заболел в результате полученной травмы на рабочем месте [6].

В настоящее время, несмотря на снижение уровней смертельного, тяжелого травматизма и травматизма с временной утратой трудоспособности, сельское хозяйство, остается одним из наиболее травмоопасных секторов экономики РК. По данным Бюро национальной статистики Агентства по стратегическому планированию и реформам РК (АСПиР РК) оно является одной из лидирующих отраслей по уровню травматизма. Впереди только строительство и обрабатывающие производства [2].

Известно, что длительное воздействие вредных производственных факторов приводит к возникновению у работников профессионально обусловленных заболеваний. В целях мониторинга за состоянием здоровья данной категории работников в Республике Казахстан действует система периодического медицинского осмотра [3].

Среди сельскохозяйственных работников наблюдается высокий уровень производственного травматизма и профессиональной заболеваемости, потому что они сталкиваются с множеством разнообразных опасных факторов, в числе которых следующие: работа с различными машинами, транспортными средствами, инструментами и животными; высокие уровни шума и вибрации; скольжение, спотыкание и падение с высоты; необходимость поднимать тяжести, совершать повторяющиеся движения и выполнять работу в неудобных позах, что приводит к нарушениям опорно-двигательного аппарата; воздействие пыли, других органических веществ, химикатов и возбудителей инфекции; а также прочие условия, характерные для сельской местности, такие как работа на солнце, при экстремальных температурах и в неблагоприятную погоду. Первое место по удельному весу в структуре травматизма занимают несчастные случаи, связанные с обслуживанием и ремонтом сельскохозяйственных машин и транспортных средств. Незначительно уступает этому виду деятельности по количеству травм уход за животными [7].

Травматизм в сельском хозяйстве наносит значительный экономический ущерб не только вследствие гибели и ухудшения состояния здоровья людей, но и благодаря снижению производительности труда и потери части продукции аграрного сектора страны. Прямой и косвенный ущерб в десятки раз больше затрат, связанных с устранением вызвавших его причин [4].

В отрасли сельского хозяйства РК в 2019 году пострадало 60 человек, из них 8 женщин (13,3\%). При этом 4 человека пострадало при групповых несчастных случаях. Из общей численности пострадавших при несчастных случаях 15 человек погибли. Данные Бюро национальной статистики АСПиР РК о количестве пострадавших и погибших работниках сельского хозяйства с 2015 по 2019 год в РК приведено в таблице 1 [2].

Таблица 1. Число пострадавших и погибших при НС, связанных с трудовой деятельностью

\begin{tabular}{|l|c|c|c|c|c|}
\hline \multicolumn{1}{|c|}{ Показатели } & 2015 & 2016 & 2017 & 2018 & 2019 \\
\hline \multicolumn{6}{|c|}{ Число пострадавших при несчастных случаях, связанных с трудовой деятельностью, } \\
\hline в том числе со смертельным исходом (человек) \\
\hline \multicolumn{2}{|c|}{ Число погибших при несчастных случаях, связанных с трудовой деятельностью (человек) } \\
\hline Всего & 73 & 8 & 13 & 11 & 15 \\
\hline $\begin{array}{l}\text { Материальные } \\
\text { последствия } \\
\begin{array}{l}\text { несчастных } \\
\text { случаев, }\end{array}\end{array}$ & 8 & 55 & 15463,3 & 12016,2 & 22416,7 \\
\hline
\end{tabular}


В результате проведенного сравнительного анализа показателей о количестве пострадавших и погибших работниках сельского хозяйства за период 2015 - 2019 гг. был отмечен снижение пострадавших в 2019 году на 62\% по сравнению с 2015годом. При этом уровень производственного травматизма со смертельным исходом в 2019 году выше на 87,5\% (15 погибших против 8 человека в 2015 г). Анализируя ситуацию по травматизму в аграрном секторе республики можно заключить, что, несмотря на сокращение абсолютного числа пострадавших каждый происшедший несчастный случай или заболевание, кроме социального урона, приносит государству большие материальные потери. Производственный травматизм оказывает негативное влияние на экономическое состояние предприятий, повышает уровень трудозатрат, снижает уровень их конкурентоспособности, вынуждает нести дополнительные расходы. Степень тяжести травмы пострадавшего приведена в таблице 2 [2].

Таблица 2. Степень тяжести травмы пострадавшего (чел.)

\begin{tabular}{|c|c|c|c|c|c|c|c|c|}
\hline & \multicolumn{2}{|c|}{ Легкая } & \multicolumn{2}{|c|}{ Средняя } & \multicolumn{2}{|c|}{ Тяжелая } & \multicolumn{2}{|c|}{ Умерло (погибло) } \\
\hline & всего & $\begin{array}{c}\text { из них } \\
\text { женщин }\end{array}$ & всего & $\begin{array}{c}\text { из них } \\
\text { женщин }\end{array}$ & всего & $\begin{array}{c}\text { из них } \\
\text { женщин }\end{array}$ & всего & $\begin{array}{c}\text { из них } \\
\text { женщин }\end{array}$ \\
\hline \multirow{4}{*}{$\begin{array}{l}\text { Сельское, } \\
\text { лесное и } \\
\text { рыбное } \\
\text { хозяйство }\end{array}$} & \multicolumn{8}{|c|}{ данные за 2019 год } \\
\hline & 8 & 1 & 17 & 4 & 20 & 3 & 15 & - \\
\hline & \multicolumn{8}{|c|}{ данные за 2018 год } \\
\hline & 14 & 1 & 20 & 2 & 23 & 4 & 11 & - \\
\hline
\end{tabular}

Травматизм с тяжелыми последствиями в сельском хозяйстве связан с воздействием на работника движущихся деталей машин. От этих причин гибнет или тяжело травмируется с повреждениями конечностей и головы более трети пострадавших. Травматизм тружеников села отличается рядом специфических повреждений. К ним относятся закрытые переломы лучевой кости, получаемые при запуске оборудования. При попадании в молотилку и другие сельскохозяйственные машины возникают открытые переломы предплечья, множественные переломы и ушибы. При падении с высоты, попадании под колеса трактора и других мобильных машин происходят повреждения позвоночника, головы и таза. При работе с домашними животными появляются травмы брюшной полости, сопровождающиеся рваными и колотыми ранами, инфицированием и внедрением в тело инородных включений. Основными причинами травматизма в сельскохозяйственном производстве являются низкий уровень организации работ, недостаточные технические знания персонала для работы на сложных машинах, нарушение правил техники безопасности, трудовой и технологической дисциплины, отсутствие надлежащего контроля производственных процессов [1].

Несмотря на тенденцию сокращения числа несчастных случаев на производстве и профессиональных заболеваний, остаются значительными социальные и экономические потери, обусловленные такими происшествиями. Данные материальных последствий несчастных случаев (общие и в расчете на одного пострадавшего) за 2018 и 2019 год приведены в таблице 3 и 4 [2].

Таблица 3. Материальные последствия несчастных случаев (тыс.тенге)

\begin{tabular}{|c|c|c|c|c|}
\hline & \multirow{2}{*}{$\begin{array}{c}\text { Материальные } \\
\text { последствия } \\
\text { несчастных } \\
\text { случаев, всего }\end{array}$} & \multicolumn{3}{|c|}{ В том числе } \\
\hline & & $\begin{array}{c}\text { Выплачено по листку } \\
\text { нетрудоспособности }\end{array}$ & $\begin{array}{c}\text { Сумма доплат до } \\
\text { прежнего } \\
\text { заработка при } \\
\text { переводе на } \\
\text { другую работу }\end{array}$ & $\begin{array}{c}\text { Выплачено } \\
\text { единовременных } \\
\text { пособий }\end{array}$ \\
\hline \multirow{4}{*}{$\begin{array}{c}\text { Сельское, лесное } \\
\text { и рыбное } \\
\text { хозяйство }\end{array}$} & \multicolumn{4}{|c|}{ данные за 2019 год } \\
\hline & 22416,7 & 6348,3 & 241,4 & 15827,0 \\
\hline & \multicolumn{4}{|c|}{ данные за 2018 год } \\
\hline & 12016,2 & 7044,1 & 670,4 & 4301,7 \\
\hline
\end{tabular}

Таблица 4. Материальные последствия несчастных случаев, в расчете на одного пострадавшего (тыс.тенге)

\begin{tabular}{|l|c|c|c|c|}
\hline & Материальные & \multicolumn{3}{|c|}{ В том числе } \\
\cline { 3 - 5 } & последствия & Выплачено по листку & Сумма доплат до & Выплачено \\
\hline
\end{tabular}




\begin{tabular}{|c|c|c|c|c|}
\hline & $\begin{array}{c}\text { несчастных } \\
\text { случаев в расчете } \\
\text { на одного } \\
\text { пострадавшего, } \\
\text { всего }\end{array}$ & нетрудоспособности & $\begin{array}{c}\text { прежнего } \\
\text { заработка при } \\
\text { переводе на } \\
\text { другую работу }\end{array}$ & $\begin{array}{c}\text { единовременных } \\
\text { пособий }\end{array}$ \\
\hline \multirow{4}{*}{$\begin{array}{c}\text { Сельское, лесное } \\
\text { и рыбное } \\
\text { хозяйство }\end{array}$} & \multicolumn{4}{|c|}{ данные за 2019 год } \\
\hline & 373,6 & 105,8 & 4,0 & 263,8 \\
\hline & \multicolumn{4}{|c|}{ данные за 2018 год } \\
\hline & 176,7 & 103,6 & 9,9 & 63,3 \\
\hline
\end{tabular}

Среди главных причин производственного травматизма в сельском хозяйстве страны: старение производственных фондов, сокращение объемов капитального и профилактического ремонта зданий, сооружений, оборудования. Слабо внедряются новая техника и безопасные технологии. Во многих организациях в нарушении Трудового кодекса РК не введены должности специалистов по охране труда и безопасности.

Профилактика несчастных случаев - это устранение их причин и предпосылок. Более половины несчастных случаев вызваны причинами организационного характера и «человеческим фактором», а именно неудовлетворительной организацией производства работ, нарушениями требований охраны труда, недостатками в обучении, нарушениями трудовой дисциплины. В должной мере обеспечить своих работников защитным инвентарем и прочим инструментарием, для защиты от предполагаемых повреждений во время исполнения своих трудовых обязанностей, в состоянии только крупные предприятия.

Для сохранения жизни и здоровья тружеников села большое значение имеют разработка и проведение мероприятий по снижению рисков смертельного и тяжелого травмирования. Конкретные мероприятия, разработанные с учетом анализа обстоятельств, видов и причин всех видов травм, в том числе, микротравм, позволят не только предотвратить несчастные случаи, но и уменьшить физический, моральный и финансовый ущерб, причиняемый ими [8].

Мероприятия, способствующие предупреждению травматизма и аварийности, включает:

- устранение технических причин связано с совершенствованием технологических процессов, заменой оборудования, имеющего конструктивные недостатки и большую изношенность, постоянным мониторингом (диагностикой) технического состояния оборудования, зданий и сооружений, инструмента и средств коллективной и индивидуальной защиты;

- совершенствование методов организации труда (качественное обучение и аттестация работников, проведение инструктажей по охране труда; эффективный распорядок режимов труда и отдыха; разработка планов профилактики производственного травматизма и ликвидации аварийных ситуаций и др.);

- создание безопасных условий труда (снижение опасных и вредных производственных факторов до нормативных величин; нормализация освещения и микроклимата в помещениях; эффективная вентиляция производственных помещений и др.);

- расширение экономических способов воздействия на травматизм и аварийность (стимулирование работы без травм и аварий);

- прогнозирование проявления опасностей и условий, при которых они могут воздействовать на работников;

- инженерные меры защиты людей от источников вредного воздействия посредством изоляции опасных элементов, а также установки барьеров между работниками и потенциальными источниками травмы;

- организационные меры включают в себя обеспечения работников индивидуальными средствами защиты;

Хотя для каждого рабочего места (или вида работ) имеются инструкции по охране труда, тем не менее, гораздо лучшую роль могут и должны играть различные плакаты, предупредительные сигналы, маркировка и окраска, знаки безопасности.

Реализация данных мероприятий по снижению воздействия главных факторов на показатели производственного травматизма позволят резко изменить динамику уровня травматизма в сторону его снижения, поскольку именно они доминируют в его формировании. Целевое финансирование 
этих мероприятий позволит в кратчайший срок и с наименьшими затратами добиться коренного перелома в снижении уровня травматизма в организациях сельского хозяйства. Работодатели реализуют меры по обеспечению безопасных условий труда в организациях, ведут профилактическую работу по предупреждению производственного травматизма, организуют проведение обучения и инструктажей по вопросам охраны труда, обеспечивают работающих средствами индивидуальной защиты и т.д. [5].

Таким образом, сельское хозяйство остается одним из наиболее сложных и травмоопасных видов экономической деятельности. Внедрение мероприятий, разработанных на основе анализа причин и обстоятельств несчастных случаев, поможет снизить уровень производственного травматизма. Руководители предприятий начинают осознавать тот факт, что бездействие в данной области негативно отражается на результатах производственной деятельности.

Ссылка на данную статью: Князов Е.Ж. (2020) О состоянии производственного травматизма на сельскохозяйственных предприятиях Казахстана. Материалы Международной практической интернет-конференции «Актуальные проблемы науки» [Challenges of Science]. Выпуск III, стр. 185-189. https://doi.org/10.31643/2020.028

\section{Литературы}

[1] Бобович Б.Б., Гарбуз Я.А. Особенности травматизма в сельском хозяйстве и его профилактика // Материалы I Всероссийской междисциплинарной научно-практической конференции. Симферополь, 5-7 октября 2017г.

[2] Бюро национальной статистики Агентства по стратегическому планированию и реформам (АСПиР) РК [Электронный pecypc] https://www.gov.kz (дата обращения: 22.10.2020).

[3] Князов Е. Ж. (2019) Оценка риска заболеваемости работников сельского хозяйства. Материалы Международной практической интернет-конференции «Актуальные проблемы науки» / Materials of International Practical Internet Conference "Challenges of Science". ISBN 978-601-323-144-0. Выпуск II, 2019. Стр.: 132-136. https://doi.org/10.31643/2019.026

[4] Воротникова А.В. Экономическая выгода от мероприятий по охране труда // Охрана труда и пожарная безопасность. 2009. N 5. С. 18-21.

[5] Гальянов И.В., Студенникова Н.С. Виды и причины несчастных случаев с тяжелыми последствиями в сельском хозяйстве и основные направления их предупреждения / Национальные интересы: приоритеты и безопасность. N 2. 2015. C. 47-60.

[6] Официальный Web-сайт Международной организации труда [Электронный ресурс] Режим доступа: http://www.ilo.org (дата обращения 22.10.20).

[7] Студенникова Н.С. Динамика показателей травматизма в сельском хозяйстве, его виды и причины // Евразийский союз ученых. 2016. N 4-2(25). С. 125-127.

[8] Шкрабак В.С., Копылов Г.Н. Краткосрочное прогнозирование травматизма в сельскохозяйственном производстве и пути его профилактики. М.: Россельхозиздат, 1985.

\section{References}

[1] Bobovich B.B., Garbuz YA.A. Osobennosti travmatizma v sel'skom khozyaystve i yego profilaktika [Features of injuries in agriculture and its prevention] // Materialy I Vserossiyskoy mezhdistsiplinarnoy nauchno-prakticheskoy konferentsii. Simferopol', 5-7 oktyabrya 2017. (In Russian).

[2] Byuro natsional'noy statistiki Agentstva po strategicheskomu planirovaniyu i reformam (ASPiR) RK [Bureau of National Statistics of the Agency for Strategic Planning and Reforms (ASPiR) of the Republic of Kazakhstan]. [Elektronnyy resurs] https://www.gov.kz (data obrashcheniya: 22.10.2020). (In Russian).

[3] Knyazov Ye. ZH. (2019) Otsenka riska zabolevayemosti rabotnikov sel'skogo khozyaystva. Materialy Mezhdunarodnoy prakticheskoy internet-konferentsii «Aktual'nyye problemy nauki»/ Materials of International Practical Internet Conference "Challenges of Science" [Assessment of the risk of morbidity in agricultural workers. Materials of International Practical Internet Conference "Challenges of Science"]. ISBN 978-601-323-144-0. Vypusk II, 2019. Str.: 132-136. (In Russian). https://doi.org/10.31643/2019.026

[4] Vorotnikova A.V. Ekonomicheskaya vygoda ot meropriyatiy po okhrane truda [Economic benefit from labor protection measures // Labor protection and fire safety. 2009. N 5.S. 18-21. (In Russian).

[5] Galyanov IV, Studennikova N.S. Vidy i prichiny neschastnykh sluchayev s tyazhelymi posledstviyami v sel'skom khozyaystve i osnovnyye napravleniya ikh preduprezhdeniya [Types and causes of accidents with severe consequences in agriculture and the main directions of their prevention] // Natsional'nyye interesy: prioritety i bezopasnost'. N 2. 2015. S. 47-60. (In Russian).

[6] Ofitsial'nyy Web-sayt Mezhdunarodnoy organizatsii truda [Official website of the International Labor Organization]. [Elektronnyy resurs] Rezhim dostupa: http://www.ilo.org (data obrashcheniya 22.10.20) . (In Russian).

[7] Studennikova N.S. Dinamika pokazateley travmatizma v sel'skom khozyaystve, yego vidy i prichiny [The dynamics of injury rates in agriculture, its types and causes] // Yevraziyskiy soyuz uchenykh. 2016. N 4-2(25). S. 125-127. (In Russian).

[8] Shkrabak V.S., Kopylov G.N. Kratkosrochnoye prognozirovaniye travmatizma v sel'skokhozyaystvennom proizvodstve i puti yego profilaktiki [Short-term forecasting of injuries in agricultural production and ways of its prevention]. M.: Rossel'khozizdat, 1985. (In Russian). 